\title{
História, Espaço e Tempo* interações necessárias
}

\author{
History, Space and Time \\ necessary interactions
}

\author{
JoSÉ D’ASSUNÇÃO BARROS \\ Doutor em História Social pela Universidade Federal Fluminense \\ Professor da Universidade Severino Sombra - www.uss.br \\ Av. Expedicionário Oswaldo de Almeida Ramos, 280, \\ Centro, Vassouras, RJ, 27700-000 \\ jose.assun@globo.com
}

RESUMO Este artigo busca esclarecer e discutir as relações entre "espaço", "tempo" e História. A ênfase é dirigida para as várias modalidades historiográficas para as quais adquirem uma significativa centralidade conceitos como o de espaço, região e território. A História Regional, a Geo-História, e as relações interdisciplinares entre História e Geografia são especialmente enfatizadas.

Palavras-chave espaço, região, Geo-História.

ABSTRACT This article attempts to clarify and discuss the relations between space, time and History. The emphasis is in the various historiographic modalities of History for which ones the concepts of space, region, and territoriality have a significant centrality. The Regional History, the Geo-History, and the interdisciplinary relations between History and Geography are specially emphasized.

Key words space, region; Geo-History.

* Artigo recebido em 17/11/2005. Aprovado em 23/03/2006. 


\section{Espaço e tempo - Territórios do historiador}

Já se disse que "a História é o estudo do homem no Tempo". A definição foi proposta por Marc Bloch por volta de meados do século XX, ${ }^{1}$ mas hoje parece tão óbvia que já deve ter sido mencionada inúmeras vezes em obras de historiografia, e certamente na maioria dos manuais de História. No entanto, quando Marc Bloch a propôs, estava confrontando esta definição a uma outra que também parecera perfeitamente óbvia aos historiadores do século XIX: "a História é o estudo do Passado Humano".

A idéia de "estudo", que aparece em ambas as definições, aliás, é particularmente sintomática, e assinala um momento no século XIX em que a história passa a ser considerada uma Ciência - uma ciência interpretativa, com seus métodos próprios e abordagens teóricas, e que deve se processar sob o métier de um novo tipo de estudioso e especialista que é o Historiador (no sentido acadêmico). O Historiador - no sentido moderno, e não no antigo - era a partir daqui esta figura de conhecimento que, no século XVIII, estivera ainda inserida embrionariamente dentro da polivalência do Filósofo de tipo iluminista como uma de suas inúmeras facetas (Voltaire, David Hume, Montesquieu e muitos outros filósofos escreveram eventualmente obras de História, ao mesmo tempo em que elaboravam ensaios voltados para a reflexão metafísica, para a estética, para a política, ou para a epistemologia).

Antes de se tornar "estudo", a História fora muitas coisas, inclusive algo que — de maneira igualmente óbvia para os homens de outro tempo - definira-se como o "registro do Passado Humano". A passagem do mero "registro" ao "estudo" é , como se disse, particularmente sintomática; mas por hora retornemos ao que há de propriamente distintivo em definir a História como "estudo do Passado Humano" ou como "Estudo do Homem no Tempo".

Quando se diz que "a História é o estudo do homem no tempo", rompese com a idéia de que a História deve examinar apenas e necessariamente o Passado. O que ela estuda na verdade são as ações e transformações humanas (ou permanências) que se desenvolvem ou se estabelecem em um determinado período de tempo, mais longo ou mais curto. Tem-se aqui o estudo de certos processos que se referem à vida humana numa diacronia - isto é, no decurso de uma passagem pelo tempo - ou que se relacionam de outras maneiras, mas sempre muito intensamente, com uma idéia de 'temporalidade' que se torna central neste tipo de estudo. Vista desta maneira a partir da terceira década do século XX, a História expandia-se extraordinariamente no campo das Ciências Humanas. Com esta nova redefinição — constantemente confirmada por uma considerável

BLOCH, Marc. Apologia da História. Rio de Janeiro: Jorge Zahar, 1997, p.55. 
e progressiva variedade de novos objetos e sub-especialidades - a História assenhorava-se por exemplo do mais recente de seus domínios: o Tempo Presente. Estudar o momento presente, com vistas a perceber como este momento presente é afetado por certos processos que se desenvolvem na passagem do tempo, ou como a temporalidade afeta de diversos modos a vida presente - incluindo aí as temporalidades imaginárias da Memória ou da Ficção - passava a ser também uma das tarefas do Historiador.

Definir a história como o estudo do homem no tempo foi portanto um passo decisivo para a expansão dos domínios historiográficos. Contudo, a definição de História, no seu aspecto mais irredutível, deve incluir ainda uma outra coordenada para além do "homem" e do "tempo". Na verdade, a História é o estudo do Homem no Tempo e no Espaço. As ações e transformações que afetam aquela vida humana que pode ser historicamente considerada dão-se em um espaço que muitas vezes é um espaço geográfico ou político, e que, sobretudo, sempre e necessariamente constituirse-á em espaço social. Mas com as expansões dos domínios históricos que começaram a se verificar no último século, este Espaço também pode ser perfeitamente um "espaço imaginário" (o espaço da imaginação, da iconografia, da literatura), e adivinha-se que em um momento que não deve estar muito distante os historiadores estarão também estudando o "espaço virtual", produzido através da comunicação virtual ou da tecnologia artificial. Pode se dar que, em um futuro próximo, ouçamos falar em uma modalidade de História Virtual na qual poderão ser examinadas as relações que se estabelecem nos espaços sociais artificialmente criados nos chats da Internet, na espacialidade imaginária das webpages ou das simulações informáticas, ou mesmo no espaço de comunicação quase instantânea dos correios eletrônicos - estas futuras fontes históricas com as quais também terão de lidar os historiadores do futuro. Mas, por hora, consideraremos apenas o Espaço nos seus sentidos tradicionais: como lugar que se estabelece na materialidade física, como campo que é gerado através das relações sociais, ou como realidade que se vê estabelecida imaginariamente em resposta aos dois fatores anteriores.

Tão logo se deu conta da importância de entender o seu ofício como a Ciência que estuda o homem no tempo e no espaço - e essa percepção também se dá de maneira cada vez mais clara e articulada em meio às revoluções historiográficas do século XX — os historiadores perceberam a necessidade de intensificar sua interdisciplinaridade com outros campos do conhecimento. Emergiu daí uma importantíssima interdisciplinaridade com a Geografia, ciência que já tradicionalmente estuda o espaço físico — e, se considerarmos outras formas de espaço como o 'espaço imaginário' e o 'espaço literário', poderíamos mencionar ainda a interdisciplinaridade com a Psicanálise, com a Crítica Literária, com a Semiótica e com tantas outras disciplinas que ofereceram novas possibilidades de métodos e técnicas 
aos historiadores. Na verdade, a noção de espacialidade foi se alargando com o desenvolvimento da historiografia do século XX: do espaço físico ao espaço social, político e imaginário, e daí até a noção do espaço como "campo de forças" que pode inclusive reger a compreensão das práticas discursivas. Neste momento, contudo, iremos nos concentrar nas noções de espaço que surgem a partir da interdisciplinaridade com a Geografia.

A interdisciplinaridade entre a História e a Geografia é estabelecida, entre outros aspectos, através de conceitos como "espaço", "território", "região", e é sobre eles que passaremos a refletir nas próximas linhas. Em uma de suas instâncias mais primárias, o espaço pode ser abordado como uma área indeterminada que existe previamente na materialidade física (e, neste caso, ainda não estaremos considerando as noções de 'espaço social', de 'espaço imaginário' e de 'espaço literário' que já foram mencionadas). Foi a partir desta noção fundadora que, na Geografia tradicional, começaram a emergir outras categorias como a de "paisagem", de "território" e de "Região" - noções de que logo os historiadores começariam a se apropriar para seus próprios fins.

Grosso modo, uma região é uma unidade definível no espaço, que se caracteriza por uma relativa homogeneidade interna com relação a certos critérios. Os elementos internos que dão uma identidade à região (e que só se tornam perceptíveis quando estabelecemos critérios que favoreçam a sua percepção) não são necessariamente estáticos. Daí que a região também pode ter sua identidade delimitada e definida com base no fato de que nela poder ser percebido um certo padrão de interrelações entre elementos dentro dos seus limites. Vale dizer, a região também pode ser compreendida como um sistema de movimento interno. Por outro lado, além de ser uma porção do espaço organizada de acordo com um determinado sistema ou identificada através de um padrão, a região quase sempre se insere ou pode se ver inserida em um conjunto mais vasto.

Esta noção mais ampla de região — como unidade que apresenta uma lógica interna ou um padrão que a singulariza, e que ao mesmo tempo pode ser vista como unidade a ser inserida ou confrontada em contextos mais amplos - abrange na verdade muitas e muitas possibilidades. Conforme os critérios que estejam sustentando nosso esforço de aproximação da realidade, vão surgindo concomitantemente as várias alternativas de dividir o espaço antes indeterminado em regiões mais definidas. Posso estabelecer critérios econômicos — relativos à produção, circulação ou consumo - para definir uma região ou dividir uma espacialidade mais vasta em diversas regiões. Posso preferir critérios culturais - considerar uma região lingüística, ou um território sobre o qual são perceptíveis certas práticas culturais que o singularizam, certos modos de vida e padrões de comportamento nas pessoas que o habitam. Posso me orientar por critérios geológicos - e estabelecer em um espaço mais vasto as divisões que se 
referem aos tipos de minerais e solos que predominam em uma área ou outra - ou posso ainda considerar zonas climáticas. A Geografia, como é de se esperar, privilegia certos critérios: muito habitualmente lança luz sobre certos aspectos que se relacionam com a materialidade física, e pode ou não relacionar estes aspectos a outros de ordem cultural (como é o caso, de modo geral, da Geografia Humana).

Uma noção importante a ser considerada aqui, antes de examinarmos como a História pode se beneficiar da abordagem geográfica, é a de "paisagem". Para a Geografia, uma paisagem é uma associação típica de características geográficas concretas que se dão numa região - ou numa extensão específica do espaço físico - e constitui um determinado um padrão visual que se forma a partir destas características que a singularizam (pensemos na paisagem de um Deserto, de uma Floresta, ou de uma Cidade). Podemos falar de uma "paisagem natural", mas também de uma "paisagem cultural" - esta última dando a perceber as interferências do homem que acabam por imprimir-se na fisionomia de um determinado espaço conferindo-lhe uma nova singularidade.

Uma paisagem geográfica, desta maneira, surge em decorrência da repetição - em uma determinada superfície ou espaço — de certos elementos produzidos por combinações de formas e que, conforme já foi dito, tanto podem ser físico-naturais como humanos. A paisagem pode coincidir com uma "região natural" — conceito que definiremos a seguir — ou pode ser derivada de um padrão cuja singularidade associa-se a um tipo de ocupação agrícola ou organização humana do espaço. Para estes últimos casos, um campo de trigo ou uma cidade de alta densidade demográfica podem ser apontados como exemplos de paisagens que têm elaboradas culturalmente as suas materialidades físicas; e a multidiversificada vegetação que recobre uma floresta virgem, ou a vasta extensão de areia que constitui um deserto inóspito, podem ser indicados como exemplos de paisagens que coincidem com "regiões naturais".

A paisagem, este padrão de visualidade que se mostra ao homem no seu estado de percepção mais espontânea, foi por motivos óbvios o primeiro grande aspecto a ser considerado pelo conhecimento geográfico no seu esforço de compreensão do mundo. Aliada ou não à percepção mais imediata de uma determinada paisagem, a noção de "região natural" cedo se constituiu em outra das mais primordiais noções geográficas, e baseia-se francamente no papel desempenhado por certos elementos físicos na organização do espaço. Pode-se considerar, neste caso, uma bacia hidrográfica, um conjunto afetado por um tipo de clima, ou uma montanha - e a partir deste ou daquele fato natural que assume uma centralidade na percepção ou análise é estabelecida em seguida uma rede de relações ou desdobramentos que terminam por definir o espaço. Exemplos clássicos de "regiões naturais" são as vastas e impenetráveis florestas que ainda 
resistem em muitas partes do globo às ações depredatórias do homem, ou a inóspita caatinga da qual a vida humana ocupa apenas os interstícios.

Estes e alguns outros são os espaços gerados pela materialidade física do mundo e pela Natureza, com nenhuma ou pouca participação do homem. A Montanha ou os rios impõem os seus limites e caminhos, uma zona climática dita suas regras. Por outro lado, ocorre também que a Política - aqui referida à vasta complexidade de estruturas de poder que estabelecem limites e centros de organização que terminam por reordenar o espaço e a materialidade de múltiplas maneiras — também produz a sua própria espacialidade. Na superfície do globo terrestre, formam-se nações, e dentro delas estados, províncias, unidades administrativas, comarcas, cidades. Todas estas divisões foram criadas pelo homem, e acabam por se superpor de um modo ou de outro às divisões impostas naturalmente, ou também por interagir com as paisagens que podem ser percebidas de diversas maneiras. Desta maneira, os aspectos físicos e os aspectos políticos - geralmente combinados de alguma forma - terminam por serem aqueles que vêm à tona mais espontaneamente quando se pensa em considerar a espacialidade. Mas, como sempre frisamos, estes aspectos podem não ser os mais importantes em função de uma determinada análise da realidade a ser empreendida, seja esta uma análise histórica, geográfica, sociológica, ou antropológica. Voltaremos a esta questão oportunamente.

Quando os historiadores deram-se conta da necessidade de - sobretudo para certos objetos históricos a serem examinados — colocar em um mesmo nível as noções de tempo e espaço, logo começaram a dialogar com conceitos mais tradicionais da Geografia como aqueles que atrás explicitamos. Uma das primeiras escolas geográficas a terem merecido a atenção dos historiadores de novo tipo, e mais particularmente da historiografia original e derivada da Escola dos Annales, foi a escola geográfica de Vidal de La Blache - geógrafo que já atuava interdisciplinarmente com historiadores desde 1905 . $^{2}$ É a contribuição deste geógrafo com relação às noções de "espaço" e de "região" que veremos em diversas obras de Lucien Febvre, e mais tarde no Mediterrâneo de Fernando Braudel. E é também um modelo derivado de Vidal La Blache que veremos nas várias monografias de "história local" que começam a ser produzidas em quantidade nos anos 1950.

O modelo geográfico de Vidal de La Blache constituiu-se por oposição à escola geográfica alemã que se constituía em torno de Ratzel. Enquanto este era francamente determinista, atribuindo uma influência quase linear do meio sobre o destino humano, Vidal de La Blache trabalhava mais

2 Vidal de La Blache contribuiu para a História da França de Ernest Lavisse com um primeiro volume intitulado Tableau de la geographie de la France. (LA BLACHE, Vidal de. Tableau de la geographie de la France. Paris : Éditions de la Table Ronde, 1903). 
propriamente com a idéia de um "possibilismo geográfico". Isto significa que, ainda que colocando o meio geográfico no centro da análise da vida humana, Vidal de La Blache buscava enfatizar as diversas possibilidades de respostas que podiam ser colocadas pelos seres humanos diante dos desafios do meio. Para além disto, tinha-se aqui uma geografia cujas noções essenciais eram constituídas a partir dos conceitos da Biologia. A moldura na qual se enquadrava a vida humana não era tanto a Terra como teatro de operações no qual intervinham os diversos fatores físicos como o clima e a base geológica, e sim a Terra enquanto matéria viva, coberta de vegetação e variedade animal, formadora de ambientes ecológicos e de possibilidades vitais.

As primeiras aplicações das concepções espaciais derivadas da escola geográfica de Vidal de La Blache apareceriam nas novas obras historiográficas que enfrentaram o desafio de estudar as macro-espacialidades. Lucien Febvre já havia se valido francamente da concepção espacial de La Blache para começar a pensar as relações entre o meio físico e a sociedade, e o resultado desta reflexão foi concretizado na obra A Terra e a Evolução Humana (1922). ${ }^{3}$ Contudo, é Fernando Braudel o primeiro a aplicar estas noções a um objeto historiográfico mais específico e de maior magnitude. 0 Mediterrâneo e o mundo mediterrânico no tempo de Felipe II (1945) — obra que se celebrizou por entremear para um mesmo objeto o exame de três temporalidades distintas (a longa, a média e a curta duração), cada qual com seu ritmo próprio - traz precisamente no primeiro volume, dedicado ao estudo de uma longa duração onde tudo se transforma muito lentamente, um paradigma que marcaria toda uma geração de historiadores: a idéia de estabelecer como ponto de partida da análise historiográfica o espaço geográfico.

Nesta obra de Braudel, como em Vidal de La Blache, o "meio" e o "espaço" são noções perfeitamente equivalentes. Oscilando entre a idéia de que o meio determina o homem, e a de que os homens instalam-se no meio natural transformando-o de modo a convertê-lo na principal base de sua vida social, Braudel termina por associar intimamente a 'civilização' e a 'macro-espacialidade'. Em Mediterrâneo ele afirma que, "uma civilização é, na base, um espaço trabalhado, organizado pelos homens e pela história", e em A Civilização Material do Capitalismo (1960) ele reitera esta relação sob a forma de uma indagação: "o que é uma civilização senão a antiga instalação de uma certa humanidade em um certo espaço?". . Esta relação íntima entre a sociedade e o meio geográfico (no sentido lablachiano) estaria

3 FEBVRE, Lucien. La terre et la evolution humaine. Paris: Albin Michel, 1922.

4 BRAUDEL, Fernando. La Méditerranée et le monde méditerranéen à l?époque de Philippe II. Paris: Flammarion, 1966, p.107; BRAUDEL, Fernando. Civilisation matérielle et capitalisme. Paris: Flammarion, 1967, p.95. 
precisamente na base da formação de uma nova modalidade historiográfica: a Geo-História.

A Geo-História introduz a geografia como grade de leitura para a história, ${ }^{5}$ e ao trazer o espaço para primeiro plano e não mais tratá-lo como mero teatro de operações - e sim como o próprio sujeito da História — possibilita o exame da longa duração, esta história quase imóvel que se desenrola sobre uma estrutura onde os elementos climáticos, geológicos, vegetais e animais encontram-se em um ambiente de equilíbrio dentro do qual se instala o homem. Rigorosamente falando, não é tanto com a idéia de um "determinismo geográfico" que Braudel trabalha em O Mediterrâneo, e sim com a idéia de um 'possibilismo' inspirado precisamente na geografia de Vidal de La Blache. Afora isto, o empreendimento a que o historiador francês se propõe nesta obra paradigmática é o de realizar uma 'espacialização da temporalidade', e mais tarde ele aprimorará também uma 'espacialização da economia', chegando ao conceito de "economias-mundo" que já se encontra perfeitamente elaborado e sustentado em exemplos históricos com A Civilização Material do Capitalismo.

O objeto do primeiro volume de O Mediterrâneo — que representa a grande originalidade desta obra dividida em três partes que se referem a cada uma das três temporalidades que marcam os ritmos da história - é a relação entre o Homem e o Espaço. É esta relação que ele pretende recuperar através de "uma história quase imóvel ... uma história lenta a desenvolver-se e a transformar-se, feita muito freqüentemente de retornos insistentes, de ciclos sem fim recomeçados ". ${ }^{6}$ A interação entre o Homem e o Espaço, as suas simbioses e estranhamentos, as limitações de um diante do outro, tudo isto não constitui propriamente a moldura do quadro que Braudel pretende examinar, mas o próprio quadro em si mesmo. Eis aqui o primeiro ato deste monumental ensaio historiográfico, e é sobre esta história quase-imóvel de longa duração - a temporalidade espacializada onde o tempo infiltra-se no solo a ponto de quase desaparecer - que se erguerá o segundo ato, a 'média duração' que rege os "destinos coletivos e movimentos de conjunto", trazendo à tona uma história das estruturas que abrange desde os sistemas econômicos até as hegemonias políticas, os estados e sociedades. Trata-se de uma história de ritmos seculares, e não mais milenares, e depois dela surgirá o último andar — a 'curta duração' que rege a história dos acontecimentos, formada por "perturbações superficiais, espumas de ondas que a maré da história carrega em suas fortes espáduas". ${ }^{7}$

DOSSE, François. A História em Migalhas. São Paulo: Editora Ensaio, 1994, p.136.
BRAUDEL, Fernando. Écrits sur l'Histoire. Paris: Flammarion, 1969, p.11.

BRAUDEL, Fernando. On History. Chicago: University of Chicago Press, 1980, p.21. 
É fácil perceber como o sujeito da história, nas duas obras monumentais de Braudel, transfere-se do homem propriamente dito para realidades que Ihe são muito superiores: o 'Espaço', no Mediterrâneo; e a 'Vida Material', na Civilização Material do Capitalismo. São estes grandes sujeitos históricos que abrem o campo de possibilismos para as subseqüentes histórias dos 'movimentos coletivos' e dos 'indivíduos'. Tal como observa Peter Burke em uma sintética mas lúcida análise de O Mediterrâneo, um dos objetivos centrais de Braudel nesta obra é mostrar que tanto a história dos acontecimentos como a história das tendências gerais não podem ser compreendidas sem as características geográficas que as informam e que, de resto, tem a sua própria história longa:

O capítulo sobre as montanhas, por exemplo, discute a cultura e a sociedade das regiões montanhosas, o conservadorismo dos montanheses, as barreiras socioculturais que separam os homens da montanha dos homens da planície, e a necessidade de muitos jovens montanheses emigrarem, tornando-se mercenários. ${ }^{8}$

O Mediterrâneo e Felipe II, enfim, é a insuperável obra prima em que Braudel pretendeu demonstrar que o tempo avança com diferenças velocidades, em uma espécie de polifonia na qual a parte mais grave coincide com a história quase imóvel do Espaço, e onde temporalidade e espacialidade praticamente se convertem uma à outra. Paradoxalmente, apesar de ter sido o primeiro a propor uma "história quase imóvel" como um dos níveis de análise, outra grande contribuição de O Mediterrâneo foi a de mostrar que tudo está sujeito a mudanças, ainda que lentas, o que inclui o próprio Espaço. De fato, a leitura de O Mediterrâneo nos mostra que o espaço definido por este grande Mar era muito maior no século XVI do que nos dias de hoje, pelo simples fato de que o transporte e a comunicação eram muito mais demorados naquele período. ${ }^{9} \mathrm{Com}$ isto, percebe-se que a espacialidade dilata-se ou comprime-se no tempo conforme consideremos um período ou outro nos quais se contraponham diferentes possibilidades dos homens movimentarem-se no espaço. Mais uma vez, homem, espaço e tempo aparecem como três fatores indissociáveis.

Se o Espaço está sujeito aos ditames do Tempo, por outro lado a Temporalidade também está sujeita aos ditames do Espaço e do meio geográfico. Apenas para dar um exemplo assinalado por François Dosse, o mesmo Mediterrâneo de Braudel também nos mostra um mundo dicotomicamente dividido em duas estações: enquanto o verão autoriza o tempo da guerra,

8 BURKE, Peter. A Escola dos Annales. São Paulo: UNESP, 1991, p.50.

9 Conforme ressalta Braudel, ?cruzar o Mediterrâneo de norte a sul levava de uma a duas semanas?, enquanto atravessá-lo de leste a oeste podia consumir ?dois ou três meses? (BRAUDEL, Fernando. La Méditerranée et le monde méditerranéen à l?époque de Philippe II, p.363). 
o inverno anuncia a estação da trégua - uma vez que "o mar revolto não permite mais aos grandes comboios militares se encaminharem de um ponto ao outro do espaço mediterrânico: é, então, o tempo dos boatos insensatos, mas também o tempo das negociações e das resoluções pacíficas". ${ }^{10}$ Desta maneira o Clima (um aspecto físico do meio geográfico) reconfigura o Espaço, e este redefine o ritmo de tempos em que se desenrolam as ações humanas. Espaço, Tempo e Homem.

A obra de Fernando Braudel também nos permite iniciar outra reflexão que retomaremos mais adiante, e que se refere à consideração de uma diferença fundamental entre "duração" e "recorte de tempo". Braudel ousou estudar o 'grande espaço' no 'tempo longo'. Quando falamos em "tempo longo" referimo-nos a uma "duração" — ou antes: a um determinado 'ritmo de duração'. O tempo longo é o tempo que se alonga, o tempo que parece passar mais lentamente. Não devemos confundir "longa duração" com "recorte extenso". O recorte de Braudel em O Mediterrâneo — pelo menos o recorte deste trecho da História de que ele se vale para orquestrar polifonicamente as três durações distintas — é o reinado de Felipe II. Braudel não estudou nesta obra um 'recorte temporal estendido'. Ele estudou um recorte tradicional, que cabe em uma ou duas gerações e que coincide com a duração de um reinado, mas examinando através deste recorte a passagem do tempo em três ritmos diferentes. Uma outra coisa seria examinar um determinado espaço — grande ou pequeno — em um recorte extenso ou estendido. Dito de outra forma, o ritmo de tempo que o historiador sintoniza em sua análise de uma determinada realidade histórico-social nada tem a ver com o "recorte temporal historiográfico" escolhido pelo historiador.

Com relação ao seu recorte espacial, Fernando Braudel havia considerado que o Mediterrâneo possuía sob certos aspectos uma unidade que transcendia as unidades nacionais que se agrupavam em torno do grande "mar interior", e que ultrapassava a polarização política entre os dois grandes impérios da época: o Espanhol e o Turco. Por outro lado, o historiador francês precisou lidar com a 'unidade na diversidade', e descreve dezenas de regiões autônomas cujos ritmos convergem para um ritmo supralocal. O mundo mediterrânico que ele descreve é constituído por um grande complexo de ambientes — mares, ilhas, montanhas, planície e desertos - e que se vê partilhado em uma pluralidade de regiões a terem sua heterogeneidade decifrada antes de ser possível propor a homogeneidade maior ditada pelo tipo de vida sugerido pelo grande Mar. Este foi o desafio enfrentado por Braudel.

Se Fernando Braudel trabalhou com o 'grande espaço', as gerações seguintes de historiadores trouxeram também a possibilidade de uma nova

10 DOSSE, François. A História em Migalhas. p.140 
tendência que abordaria o 'pequeno espaço'. Esta nova tendência, que se fortalece nos anos 1950, ficou conhecida na França como 'História Local'. Também aqui a contribuição da Geografia derivada de Vidal de La Blache destaca-se com particular nitidez, ajudando a configurar um conceito de Região que logo passaria a ser utilizado pelos Historiadores para o estudo de micro-espaços ou espaços localizados, em muitos sentidos dotados de uma homogeneidade bem maior do que os macro-espaços que haviam sido examinados por Braudel. Do macro-espaço que abriga civilizações, a historiografia moderna apresentava agora a possibilidade de examinar os micro-espaços que abrigavam populações localizadas, fragmentos de uma comunidade nacional mais ampla. A História Local nascia, aliás, como possibilidade de confirmar ou corrigir as grandes formulações que haviam sido propostas ao nível das histórias nacionais. A História Local — ou História Regional, como passaria a ser chamada com um sentido um pouco mais específico - surgia precisamente como a possibilidade de oferecer uma iluminação em detalhe de grandes questões econômicas, políticas, sociais e culturais que até então haviam sido examinadas no âmbito das dimensões nacionais.

O modelo de compreensão do Espaço proposto pela escola de Vidal La Blache funcionou adequadamente para diversos estudos associados a esta historiografia européia dos anos 1950 que lidava com aquilo que Pierre Goubert - um dos grandes nomes da 'História Local' — chamava de "unidade provincial comum", e que ele associava a unidades "tal como um country inglês, um contado italiano, uma Land alemã, um pays ou bailiwick franceses". ${ }^{11}$ Nestes casos e em outros, o espaço escolhido pelo historiador coincidia de modo geral com uma unidade administrativa e muitas vezes com uma unidade bastante homogênea do ponto de vista geográfico ou da perspectiva de práticas agrícolas. Também se tratava habitualmente de zonas mais ou menos estáveis - bem ao contrário do que ocorria em países como os da América Latina durante o período colonial, onde devemos considerar a ocorrência muito mais freqüente de "fronteiras móveis". A espacialidade tipicamente européia em certos recortes temporais - que não coincide com a de outras áreas do planeta e para todos os períodos históricos — permitiu que fosse aproveitado por aqueles historiadores que começavam a desenvolver estudos regionais, cobrindo todo o Antigo Regime, um modelo onde o espaço podia ser investigado e apresentado previamente pelo historiador, como uma espécie de moldura onde os acontecimentos, práticas e processos sociais se desenrolavam. Freqüentemente, e até os anos 1960, as monografias derivadas da chamada Escola dos Annales apresentavam previamente a Introdução Geográfica, e

11 GOUBERT, Pierre. História Local. In: História \& Perspectivas, Uberlândia, 6, p.45-47, Jan/Jun 1992 
depois vinha a História, a organização social, as ações do homem. A possibilidade de este modelo funcionar, naturalmente, dependia muito do objeto que se tinha em vista, para além dos padrões da espacialidade européia nos períodos considerados.

A crítica que depois se fez a este modelo onde o espaço era como que dado previamente - tal como aparecia nas propostas derivadas da escola de Vidal de La Blache - é que na verdade estava sendo adotado um conceito não-operacional de Região. As Regiões vinham definidas previamente, como que estabelecidas de uma vez por todas, e bastava o historiador ou o geógrafo escolher a sua para depois trabalhar nela com suas problematizações específicas. Freqüentemente - quando a região coincidia com um recorte político-administrativo que permanecera sem maiores alterações desde a época estudada até o tempo presente - isto representava uma certa comodidade para o historiador, que podia buscar as suas fontes exclusivamente em arquivos concentrados nas regiões assim definidas.

Em seu célebre artigo sobre "A História Local", Pierre Goubert chama atenção para o fato de que a emergência da história local dos anos 1950 havia sido motivada precisamente por uma combinação entre o interesse em estudar uma maior amplitude social (e não mais apenas os indivíduos ilustres, como nas crônicas regionais do século XIX) e alguns métodos que permitiriam este estudo para regiões mais localizadas - mais particularmente as abordagens seriais e estatísticas, capazes de trabalhar com dados referentes a toda uma população de maneira massiva. Ao trabalhar em suas pequenas localidades, os historiadores poderiam desta maneira fixar sua atenção "em uma região geográfica particular, cujos registros estivessem bem reunidos e pudessem ser analisados por um homem sozinho". ${ }^{12} \mathrm{~A}$ coincidência entre a região examinada e uma unidade administrativa tradicional como a paróquia rural ou o pequeno município, podemos acrescentar, permitia por vezes que o historiador resolvesse todas as suas carências de fontes em um único arquivo, ali mesmo encontrando e constituindo a série a partir da qual poderia extrair os dados sobre a população e a comunidade examinada.

Com o progressivo surgimento dos novos problemas e objetos que a expansão dos domínios historiográficos passou a oferecer cada vez mais no decurso do século XX, o modelo de região derivado da escola geográfica de La Blache começou a ser questionado precisamente porque deixava encoberta a questão essencial de que qualquer delimitação espacial é sempre uma delimitação arbitrária, e também de que as relações entre o homem e o espaço modificam-se com o tempo, tornando inúteis (ou não-operacionais)

2 GOUBERT, Pierre. História Local, p.49 
delimitações regionais que poderiam funcionar para um período mas não para outro. Uma paisagem rural facilmente pode se modificar a partir da ação do homem, o que mostra a inoperância de considerar regiões geográficas fixas - e isto se mostra especialmente relevante para os estudos da América Latina no período colonial, mais ainda do que para os estudos relativos à Europa do mesmo período. ${ }^{13}$ De igual maneira, um território (voltaremos a este conceito) não existe senão com relação ao âmbito de análises que se tem em vista, aos aspectos da vida humana que estão sendo examinados (se do âmbito econômico, político, cultural ou mental, por exemplo).

Atrelar o espaço ou o território historiográfico que o historiador constitui a uma pré-estabelecida região administrativa, geográfica (no sentido proposto por La Blache), ou de qualquer outro tipo, implicava em deixar escapar uma série de objetos historiográficos que não se ajustam a estes limites. A mesma comodidade arquivística que pode favorecer ou viabilizar um trabalho mais artesanal do historiador - capacitando-o para dar conta sozinho de seu objeto sem abandonar o seu pequeno recinto documental — também pode limitar e empobrecer as escolhas historiográficas. Uma determinada prática cultural, conforme veremos oportunamente, pode gerar um território específico que nada tenha a ver com o recorte administrativo de uma paróquia ou município, misturando pedaços de unidades paroquiais distintas ou vazando municípios. Do mesmo modo, uma realidade econômica ou de qualquer outro tipo não coincide necessariamente com a região geográfica no sentido tradicional.

A crítica aos modelos de recorte regional-administrativo, ou de recortes geográficos à velha maneira de Vidal La Blache, não surgiram apenas das novas buscas historiográficas, mas também de desenvolvimentos que se deram no próprio seio da Geografia Humana. Tal ressalta Ciro Flamarion Cardoso em um ensaio bastante importante sobre a História Agrária, à altura dos anos 1970 o conceito de "região" derivado da escola de Vidal de la Blache começou a ser radicalmente criticado por autores como Yves Lacoste $^{14}$ - que sustentavam que a realidade impõe o reconhecimento de "especialidades diferenciais, de dimensões e significados variados, cujos limites se recortam e se superpõem, de tal maneira que, estando num ponto qualquer, não estaremos dentro de um, e sim de diversos conjuntos espaciais definidos de diferentes maneiras". ${ }^{15}$

A idéia de tratar sob o ponto de vista das "espacialidades superpostas" a materialidade física sobre a qual se movimenta o homem em sociedade,

13 Mesmo para períodos posteriores, deve ser observada uma distinção na espacialidade de certos países que adquiriram centralidade em termos de domínio econômico e os chamados países subdesenvolvidos. Milton Santos observa que "descontínuo, instável, o espaço dos países subdesenvolvidos é igualmente multipolarizado, ou seja, é submetido e pressionado por múltiplas influências e polarizações oriundas de diferentes tipos de decisão" (SANTOS, Milton. O Espaço Dividido. São Paulo: EDUSP, 2004, p.21).

14 LACOSTE, Yves. La geographie, ça sert d'abord à faire la guerra. Paris : Maspéro, 1976.

15 CARDOSO, Ciro Flamarion. Agricultura, Escravidão e Capitalismo. Petrópolis: Editora Vozes, 1979. 
incluindo sistemas diversificados que vão da rede de transportes à rede de conexões comerciais ou ao estabelecimento de padrões culturais, aproxima-se muito mais da realidade vivida do que o encerramento do espaço em regiões definidas de uma vez para sempre, e associadas apenas aos recortes administrativos e geográficos que habitualmente aparecem nos mapas. A realidade, em qualquer época, é necessariamente complexa, mesmo que esta complexidade não possa ser integralmente captada por nenhuma das ciências humanas, por mais que estas desenvolvam novos métodos para tentar apreender a realidade a partir de perspectivas cada vez mais enriquecidas. Voltaremos oportunamente a este aspecto, quando discutirmos os recortes a que o historiador é obrigado a se render na operação historiográfica através da qual busca apreender a vida humana.

Outro geógrafo importante para a discussão do espaço, embora ainda pouco utilizado pelos historiadores, é Claude Raffestin, que faz uma distinção bastante interessante entre o "espaço" e o "território". Segundo Raffestin, "o território se forma a partir do espaço, é o resultado de uma ação conduzida por um ator sintagmático (ator que realiza um programa) em qualquer nível. Ao se apropriar de um espaço, concreta ou abstratamente (por exemplo, pela representação), o ator 'territorializa' o espaço". ${ }^{16}$ Obviamente que a definição de "espaço" proposta por Raffestin, necessariamente ligada à materialidade física, deixa de fora as possibilidades de se falar em outras modalidades de espaço - como o "espaço social", o "espaço imaginário", o "espaço virtual" - que se constituem no próprio momento da ação humana. De qualquer modo, o sistema conceitual proposto por Raffestin é importante porque chama atenção para o fato de que a territorialização do espaço ocorre não apenas com as práticas que se estabelecem na realidade vivida, como também com as ações que são empreendidas pelo sujeito de conhecimento:

'Local' de possibilidades, [o espaço] é a realidade material preexistente a qualquer conhecimento e a qualquer prática dos quais será o objeto a partir do momento em que um ator manifeste a intenção de dele se apoderar. Evidentemente, o território se apóia no espaço, mas não é o espaço. É uma produção, a partir do espaço. Ora, a produção, por causa de todas as relações que envolve, se inscreve num campo de poder. Produzir uma representação do espaço já é uma apropriação, uma empresa, um controle portanto, mesmo se isso permanece nos limites de um conhecimento.. ${ }^{17}$

Vale ainda lembrar que a consciência de uma territorialidade que é transferida ao espaço pode transcender o mundo humano. Também os animais de várias espécies, que não apenas o homem, costumam territorializar o

16 RAFFESTIN, Claude. Por uma Geografia do Poder.

17 RAFFESTIN, Claude. op.cit., p.144. 
espaço com as suas ações e com gestos que passam a delinear uma nova representação do espaço. O lobo que "marca o seu território" cria para si (e pretende impor a outros de sua espécie) uma representação do espaço que o redefine como extensão de terra sob o seu controle. Demarcar o território é demarcar um espaço de poder. No âmbito da Macro-Política, não é senão isto o que fazem os Estados-Nações ao constituir e estabelecer um rigoroso controle sobre suas fronteiras. ${ }^{18}$

Mas a noção de território pode ser levada adiante. A combinação das já discutidas proposições de Yves Lacoste com os conceitos de "espaço" e "território" propostos por Claude Raffestin também permitiriam falar mais propriamente de 'territorialidades superpostas'. Em sua realidade vivida, os seres humanos - e de formas extremamente complexas - estão constantemente se apropriando do espaço sobre o qual vivem e estabelecem suas diversificadas atividades e relações sociais. Um mesmo homem, no seu agir cotidiano e na sua correlação com outros homens, vai produzindo territórios que apresentam maior ou menor durabilidade. Ao se apropriar de determinado espaço e transformá-lo em sua propriedade - seja através de um gesto de posse ou de um ato de compra em um sistema onde as propriedades já estão constituídas - um sujeito humano define ou redefine um território. Ao se estabelecer um determinado sistema de plantio sobre uma superfície natural, ocorre aí uma nova territorialização do espaço, claramente caracterizada por uma nova "paisagem" produzida culturalmente e por uma produção que implicará em controle e conferirá poder.

O território que se produz e se converte em propriedade fundiária — ou em unidade política estável para considerar um nível mais amplo — pode existir em uma duração bastante longa antes de ser tragado por um novo processo de reterritorialização. Contudo, se um homem exerce a profissão de professor, ou a função de político, no momento de exercício destas funções ele poderá estar territorializando uma sala de aula ou um palanque por ocasião de um comício político, por exemplo, constituindo-se estes em territórios de curtíssima duração. A vida humana é eterno devir de territórios de longa e curta duração, que se superpõem e se entretecem ao sabor das relações sociais, das práticas e representações. E, sob certo ângulo, a História Política é o estudo deste infindável devir de territorialidades que se constituem a partir dos espaços físicos, mas também dos espaços sociais, culturais e imaginários.

Os caminhos mais recentes da Geografia Humana também convergiram para considerar o espaço como "campo de forças". É de um "espaço

18 ?Por território entende-se a extensão apropriada e usada. Mas o sentido da palavra territorialidade como sinônimo de pertencer àquilo que nos pertence ... esse sentido de exclusividade e limite ultrapassa a raça humana? (Milton SANTOS e Maria Laura SILVEIRA, O Brasil? território e sociedade no início do século XX. Rio de Janeiro: Record, 2003, p.19). 
social" que Milton Santos está falando quando propõe associar a noção de campo a uma Geografia Nova. ${ }^{19}$ Abordando a questão do ponto de vista do materialismo dialético, ele chama atenção para o fato de que o espaço humano é, em qualquer período histórico, resultado de uma produção. "O ato de produzir é igualmente o ato de produzir espaço". O homem, que devido à sua própria materialidade física é ele mesmo espaço preenchido com o próprio corpo, além de ser espaço também está no espaço e produz espaço.

Mas poderíamos mais uma vez unir estas pontas e dizer que "o ato de produzir é igualmente o ato de produzir territórios". Cultivar a terra é dominar a terra, é impor-lhe novos sentidos, é apartá-la do espaço indeterminado inclusive frente a outros homens, é exercer um poder e obrigar-se a um controle. Fabricar mercadorias (ou controlar a produção de mercadorias) é invadir um espaço, é adentrar esse complexo campo de forças formado pela produção, circulação e consumo, e tudo isto passa também por exercer um controle sobre o espaço vital dos trabalhadores, sobre o seu tempo. Produzir idéias é se assenhorear de espaços imaginários e, de algum modo, exercer através destes espaços diversificadas formas de poder. A produção de discursos, por fim, implica em se adequar a uma espécie de territorialização da fala, na qual devem ser reconhecidas aquelas regras, limites e interdições que foram tão bem estudadas por Michel Foucault. ${ }^{20}$ Em todos estes casos, enfim, a produção estabelece territórios, redefine espaços. E de todos estes tipos de espaços deve se apropriar o historiador no exercício de seu ofício.

19 SANTOS, Milton. Por uma Geografia Nova. Rio de Janeiro: 1974, p.174

20 "Em toda sociedade a produção do discurso é ao mesmo tempo controlada, selecionada, organizada e distribuída por certo número de procedimentos que têm por função conjurar seus poderes e perigos, dominar seu acontecimento aleatório, esquivar sua pesada e terrível materialidade" (FOUCAULT, Michel. A Ordem do Discurso. São Paulo: Edições Loyola, 1996, p.8-9). 